\title{
MTI TABEK GADANG SEBAGAI LEMBAGA PENDIDIKAN ISLAM MODERN DI KABUPATEN 50 KOTA (TINJAAN HISTORIS)
}

\author{
Suryadi Fajri, Safri Mardison \\ Prodi Tadris IPS-Sejarah Fakultas Tarbiyah dan Keguruan UIN IB Padang
}

\begin{abstract}
Abstrak
Tulisan ini dilatarbelakangi oleh ketertarikan penulis mengungkap kembali seperti apa sejarah Madrasah Tarbiyah Islamiyah Tabek Gadang pada masa lalu, di mana sejarah mengatakan bahwa Madrasah Tarbiyah Islamiyah Tabek Gadang pernah menjadi salah satu madrasah yang dikenal mempunyai andil besar dalam pendidikan Islam di Kabupaten Lima Puluh Kota khususnya Kecamatan Guguak. Rumusan masalah dalam penelitian ini adalah sejarah berdirinya Madrasah Tarbiyah Islamiyah (MTI) Tabek Gadang dan perkembangan Madrasah Tarbiyah Islamiyah (MTI) Tabek Gadang dari segi kepemimpinan, kesiswaan, kurikulum, tenaga pengajar dan sarana prasarana. Batasan masalah penelitian ini adalah, Pertama, batasan spasial, yaitu kenagarian VII Koto Talago Kecamatan Guguak Kabupaten Lima Puluh Kota dimana Madrasah Tarbiyah Islamiyah Tabek Gadang berdiri. Kedua, batasan temporal, yaitu dari tahun 1990 sampai 2015, di mana tahun 1990 merupakan awal berdirinya kembali Madrasah Tarbiyah Islamiyah Tabek Gadang setelah ditutup selama empat tahun dari tahun 1984 sampai 1990.
\end{abstract}

Kata Kunci : MTI, Tabek Gadang, Pendidikan

\section{Pendahuluan}

Pendidikan Islam di Indonesia semakin berkembang sejak awal abad ke-20. Hal ini tampak dari perubahan-perubahan besar di kalangan Islam yang dikenal dengan gerakan pembaharuan Islam. Gerakan ini mengakibatkan sistem pendidikan tradisional keagamaan mengalami perubahan kesistem pendidikan modern. Hal ini ditandai dengan munculnya Madrasah. Pendidikan Islam dalam bentuk madrasah, diorganisir yang memiliki kurikulum, manajemen dan administrasi pengelolaan, serta tenaga pengajar (guru) dengan sistem gaji bulanan. Sementara murid yang berhasil menyelesaikan pendidikannya pada tingkat tertentu misalnya setelah tamat Tsawiyah, Aliyah dan sebagainya diberi ijazah atau surat keterangan tamat (Karela Steenbrink, 1986: 10-12).

Madrasah merupakan salah satu lembaga pendidikan Islam yang mempunyai tujuan khusus, akan tetapi pendidikan Islam tidak boleh terpisahkan dari pendidikan nasional, artinya madrasah harus dapat memberikan kontribusi terhadap tujuan pendidikan nasional, karena pada dasarnya pendidikan madrasah adalah proses untuk pendewasaan peserta didik melalui perbuatan 
dan tindakan makhluk yang direncanakan dari yang tidak tahu menjadi tahu untuk bekalnya nanti yang akan dibutuhkan pada waktu dewasa.

Dengan perkembangan yang terjadi pada lembaga pendidikan yang awal mulanya hanya pondok pesantren dan surau-surau (untuk di ranah Minang), kemudian dikembangkanlah suatu lembaga pendidikan yang lebih lengkap bagi seseorang dalam menggali potensi dengan berbagai kajian ilmu yang lebih banyak diberikan atau diajarkan dalam lembaga madrasah tersebut, juga lembaga ini telah dibenahi dengan sistem manajemen administrasi yang baik dan juga kurikulumnya. Perkembangan ini dipengaruhi oleh sekolah-sekolah yang dibangun oleh kolonial Belanda, juga karena gerakan pembaharuan yang terjadi di Indonesia serta sebagai respon terhadap kebijakan pendidikan Hindia-Belanda.

Perkembangan baru ini dapat dilihat sebagai gejala modernisasi dalam bidang pendidikan Islam. Dalam hal ini Sumatera Barat pada awal abad ke-20 merupakan tempat awal tumbuhnya gerakan pembaharuan pemikiran Islam di Indonesia, lalu dari sini paham pembaharuan tersebut menyebar ke daerah lainnya.

Seiring dengan tuntutan zaman, lembaga-lembaga pendidikan Islam yang pada awalnya bersifat non formal seperti surau-surau yang ada di Minangkabau banyak yang berkembang menjadi sebuah lembaga Pendidikan Agama Islam modern, salah satunya yaitu Madrasah Tarbiyah Islamiyah Tabek Gadang.

Madrasah Tarbiyah Islamiyah Tabek Gadang telah ada sejak tahun 1906 dalam bentuk surau yang didirikan oleh Syekh Abdul Wahid Ash Shalihi. Pada tahun 1928 beliau mengubah bentuk majelis pendidikannya menjadi Madrasah Tarbiyah Islamiyah. Namun setelah Syekh Abdul Wahid Ash Shalihi meninggal pada tahun 1950 Madrasah Tarbiyah Islamiyah Tabek Gadang mengalami kemunduran, bahkan Madrasah Tarbiyah Islamiyah Tabek Gadang ini sempat mati pada tahun 1984-1989 dan berdiri kembali pada tahun 1990.

Menurut Mulyadi yang juga merupakan cucu pendiri sekolah tersebut mengatakan bahwa Madrasah Tarbiyah Islamiyah Tabek Gadang telah ada jauh sebelum kemerdekaan dalam bentuk surau namun dalam perkembangannya sempat berhenti dan berdiri kembali pada tahun 1990 (Mulyadi, Wawancara, 2 September 2014).

Setelah berdiri kembali pada tahun 1990 sampai saat ini Madrasah Tarbiyah Islamiyah Tabek Gadang telah banyak mengalami perkembangan dari berbagai hal seperti tenaga pengajar yang dulunya rata-rata tamatan Madrasah Tarbiyah Islamiyah itu sendiri, sekarang guru-guru 
yang mengajar di Madrasah ini hampir seluruhnya telah menamatkan pendidikan di perguruan tinggi dan juga beberapa diantaranya telah diangkat menjadi Pegawai Negri Sipil (PNS). Begitu juga dengan sarana dan pra sarana, atau manajemen administrasi sekolah dan kurikulum Madrasah Tarbiyah Islamiyah ini telah banyak mengalami perkembangan sesuai dengan perkembangan pendidikan dan IPTEK saat ini. Lembaga Pendidikan Agama Islam modern tidak hanya dituntut untuk menciptakan santri-santri yang menguasai ilmu Agama sebagai $d a ' i$, tetapi juga dituntut untuk melahirkan santri-santri atau siswa yang dapat melanjutkan ke Perguruan Tinggi dan bisa terjun ke dunia kerja nantinya serta dapat bersaing dalam dunia dimana perkembangan IPTEK telah lebih maju dengan tetap memelihara karakteristiknya sebagai sekolah yang berciri khas agama Islam sesuai dengan implementasi ajaran ahlussunah wal jamaah.

Madrasah mempunyai karakter yang sangat spesifik bukan hanya melaksanakan tugas pendidikan dan pengajaran agama, tetapi juga mempunyai tugas untuk memberikan bimbingan hidup dalam masyarakat. Madrasah yang membawa fungsi teologis demikian, akan paralel dengan kesadaran masyarakat yang dilandasi oleh kebutuhan memperdalam dan mengamalkan ilmu-ilmu agamanya (Muhaimin, 2005: 45).

\section{Metode Penelitian}

\section{Jenis Penelitian}

Pada tahap awal yang penulis lakukan adalah penelitian kualitatif yaitu penelitian lapangan (Field Research) yang mana penelitian ini dilakukan di Madrasah Tarbiyah Islamiya Tabek Gadang Kenagarian VII Koto Talago Kecamatan Guguak Kabupaten Lima Puluh Kota, dan Penelitian Historis yang (Historical Research) tujuan dari penelitian historis ini adalah untuk membuat rekontruksi masa lampau secara sistematis dan objektif dengan cara dengan cara mengumpulkan, mengevaluasi, memverifikasikan serta mensistesiskan bukti untuk menegakkan fakta dan memperoleh kesimpulan yang kuat.

\section{Metode Sejarah}

Sejarah merupakan rekontruksi masa lampau yang terkait pada prosedur penelitian ilmiah, untuk memperoleh sejarah yang ilmiah maka diperlukan metode penelitian. Metode yang digunakan dalam penulisan skripsi ini adalah metode sejarah, karena obyek dari penelitian ini bertujuan untuk mendeskripsikan dan menganalisa peristiwa-peristiwa masa lampau (Mestika 
Zed, 1999: 1). Maka metode yang dipakai adalah metode historis yaitu penelitian yang berusaha untuk mengkaji dan menganalisa secara kritis terhadap rekaman dan peninggalan masa lampau. Metode sejarah tersebut adalah:

a. Heuristik (Mengumpulkan Sumber)

Heuristik yaitu pengumpulan sumber atau data sebanyak mungkin, sumber yang diperoleh diklasifikasikan menjadi dua yaitu sumber primer dan sumber sekunder (Renier ,G.J., 1997: 113). Sumber primer adalah kesaksian secara langsung baik para pelaku maupun para saksi dengan mata kepala sendiri atau sumber tangan pertama. Sedangkan sumber sekunder adalah sumber yang dapat mendukung dan mempertegas sumber primer. Sumber primer dan sekunder didapatkan melalui:

1) Dalam mencari dan mengumpulkan data pertama sekali yang penulis lakukan adalah melakukan studi pustaka dengan mencari literatur dan sumber yang berhubungan dengan penelitian yang penulis lakukan seperti buku, dokumen, arsip, artikel, dan yang lain yang berhubungan dengan masalah yang diteliti.

2) Setelah memperoleh data dari sumber awal maka penulis melanjutkan pada langkah kedua dalam heuristic yaitu wawancara. Sebelum penulis melakukan wawancara terlebih dahulu penulis membuat daftar pertanyaan atau pedoman wawancara, wawancara yang penulis lakukan dengan mengajukan pertanyaan yang berkaitan dengan penelitian ini kepada informan.

3) Sebagai langkah ketiga dalam penelitian heuristic ini adalah melakukan observasi lapangan dengan mengunjungi Jorong Padang Jopang Kenagarian VII Koto Talago Kecamatan Guguak Lima Puluh Kota, karena disinilah berdirinya Madrasah Tarbiyah Islamiyah Tabek Gadang.

Di sini selain penulis mengumpulkan sumber data berupa arsip, penulis juga melakukan wawancara kepada beberapa informan seperti, anak dan cucu pendiri madrasah, ketua yayasan, alumni Madrasah Tarbiyah Islamiyah Tabek Gadang, tokoh masyarakat, kepala sekolah, guru-guru Madrasah Tarbiyah Islamiyah Tabek Gadang, kariyawan, tata usaha Madrasah Tarbiyah Islamiyah Tabek Gadang dan siswa Madrasah Tarbiyah Islamiyah Tabek Gadang.

b. Kritik Sumber 
Kritik sumber merupakan tahap kedua dalam penulisan sejarah, dimana sumber atau data yang diperoleh dilakukan pengkritikan terlebih dahulu maupun intern maupun ekstern. Kritik sumber ini dapat dikatakan sebagai langkah dalam penyeleksian data (Irhas A. Shamad, 2004: 91) Dari hasil kritik ekstern dan intern ini maka akan didapatkan sumber-sumber yang layak dan patut untuk dijadikan sebagai rujukan dan pedoman dalam mengambil informasi tentang tokoh tersebut.

Setelah penulis melakukan wawancara dengan beberapa orang informan, maka dilakukan lah kritik sumber dengan mengevaluasi kembali informan dan hasil wawancara yang didapat. Di sini penulis tidak memuat seluruh hasil wawancara yang penulis dapat karena ada beberapa informan yang tidak mencukupi syarat dan memberikan data yang tidak valid seperti siswa Madrasah Tarbiyah Islamiyah Tabek Gadang yang belum cukup umur, seorang tokoh masyarakat yaitu Dt. Sori Marajo yang lahir dan besar di perantauan dan tiga orang guru yang belum cukup satu tahun mengajar di Madrasah Tarbiyah Islamiyah Tabek Gadang.

\section{c. Analisis atau Interpretasi}

Sintesis yaitu analisis dan interpretasi (penafsiran kembali) terhadap data yang terkumpul, dengan cara pengelompokan data dengan menganalisa fakta mana yang bisa langsung kita gunakan ataupun didukung dengan fakta lainnya, yang kemudian merangkai data yang relevan dengan kajian dan dapat dipercaya kebenarannya (Irhas A. Shamad, 2004: 99).

Dalam melakukan wawancara, bermacam-macam cara informan memberikan keterangan tentang Sejarah Madrasah Tarbiyah Islamiyah Tabek Gadang, ada yang menyampaikan dengan bahasa daerah, cerita yang tidak terstruktur, bahasa yang terlalu tinggi sehingga sulit untuk dimengerti dan ada yang lebih banyak menceritakan hal ghaib yang bersifat mitos daripada mengungkapkan fakta. Oleh sebab itu, maka penulis melakukan analisa dan interpretasi terhadap data yang diperoleh yaitu dengan menganalisa kembali dan menafsirkan keterangan-keterangan yang diberikan informan, lalu mendeskripsikannya dengan menggunakan bahasa yang penulis pahami. Selain dari itu sumber fakta yang telah disusun berdasarkan sumber yang teruji dihubungkan antara yang satu dengan yang lainnya dengan menggunakan eksplanasi dan intrepretasi. Sehingga fakta tersebut terangkai saling berhubungan dan menjadi alur cerita sejarah yang logis berupa Sejarah Madrasah Tarbiyah Islamiyah Tabek Gadang di Kecamatan Guguak Kabupaten Lima Puluh Kota. 


\section{d. Historiografi (Penulisan Sejarah)}

Historiografi merupakan salah satu tahapan dalam empat tahap dalam proses pengerjaan penulisan sejarah. Historiografi sebagai proses penulisan laporan hasil penelitian sejarah, penelitian sejarah berakhir dengan pembuatan laporan hasil penelitian artinya suatu hasil penelitian tidak pernah ada kalau tidak ditulis atau dituangkan ke dalam bentuk tulisan atau laporan (Mestika Zed, 1999: 59)

Penulis akan berusaha semampu mungkin untuk memaparkan hasil penelitian yang telah ada dengan merangkai fakta-fakta yang ada, sehingga membentuk karya tulis yang ilmiah. Dalam pemaparan ini penulis akan menggunakan pendekatan deskriptif naratif dan tidak tertutup kemungkinan menggunakan pendekatan deskriptif analisa. Sebagai pedoman penulisan maka yang penulis pakai adalah buku metode penulisan sejarah. Maka dalam penulisan hasil penelitian ini merupakan gabungan dari deskriptif naratif dan deskriptif analisis (Mestika Zed, 1999: 60)

\section{Hasil Penelitin}

\section{Periode 1990-1993}

Periode ini merupakan awal berdirinya kembali Madrasah Tarbiyah Islamiyah Tabek Gadang setelah ditutup selama 4 tahun. Pada masa ini dapat dilihat perkembangannya dari beberapa segi :

a. Kepemimpinan

Madrasah Tarbiyah Islamiyah Tabek Gadang pada masa ini dipimpin oleh Muhammad Khatib. Muhammad Khatib atau lebih dikenal dengan Dt. Katumanggungan merupakan seorang alim ulama atau juru dakwah yang memiliki latar belakang pendidikan Madrasah Tarbiyah Islamiyah. Beliau pada awalnya diminta oleh H.Yusri Anwar untuk mengajar beberapa orang siswa yang mendaftar sebelum Madrasah Tarbiyah Islamiyah Tabek Gadang diresmikan dan mengadakan wirid pengajian mingguan untuk jemaah sekitar yang diadakan di Tabek Gadang. Berkat kiprahnya dalam mengelola sekolah serta keilmuannya tentang agama cukup mendalam maka pengurus atau pihak Yayasan yang diketuai oleh H.Yusri Anwar menunjuk beliau sebagai kepala sekolah pertama Madrasah Tarbiyah Islamiyah Tabek Gadang setelah berdiri kembali, beberapa bulan sebelum kepergian H.Yusri Anwar (Fachrul Razi, Wawancara, 08 Mei 2016).

Menjabat sebagai kepala sekolah yang pertama setelah beberapa tahun ditutup merupakan suatu tantangan yang cukup berat bagi Dt. Katumanggungan, karena beliau harus berusaha 
mengembalikan kejayaan di masa lalu Madrasah Tarbiyah Islamiyah Tabek Gadang. Tapi berkat usaha dan kerja keras Dt. Katumanggungan perlahan Madrasah Tarbiyah Islamiyah Tabek Gadang mulai berkembang dan siswa mulai berdatangan dari berbagai daerah hingga pada tahun 1993. Dt. Katumanggungan mengundurkan diri dari Madrasah Tarbiyah Islamiyah Tabek Gadang karena kondisi kesehatan beliau mulai menurun.

b. Siswa

Madrasah Tarbiyah Islamiyah Tabek Gadang telah berdiri kembali dengan siswa pertamanya sebanyak 22 orang. Pada tahun-tahun berikutnya jumlah siswa Madrasah Tarbiyah Islamiyah Tabek Gadang terus bertambah sebagaimana yang tercantum pada tabel berikut :

Tabel 4.5

Jumlah Siswa Madrasah Tarbiyah Islamiyah Tabek Gadang Tahun 1990-1993

\begin{tabular}{|c|c|c|}
\hline No & Tahun & Jumlah Siswa \\
\hline 1 & 1990 & 22 orang \\
\hline 2 & 1992 & 46 orang \\
\hline 3 & 1993 & 62 orang \\
\hline
\end{tabular}

Sumber: Arsi Madrasah Tarbiyah Islamiyah Tabek Gadang

Untuk muatan kurikulum Madrasah Tarbiyah Islamiyah Tabek Gadang dapat dilihat pada data berikut:

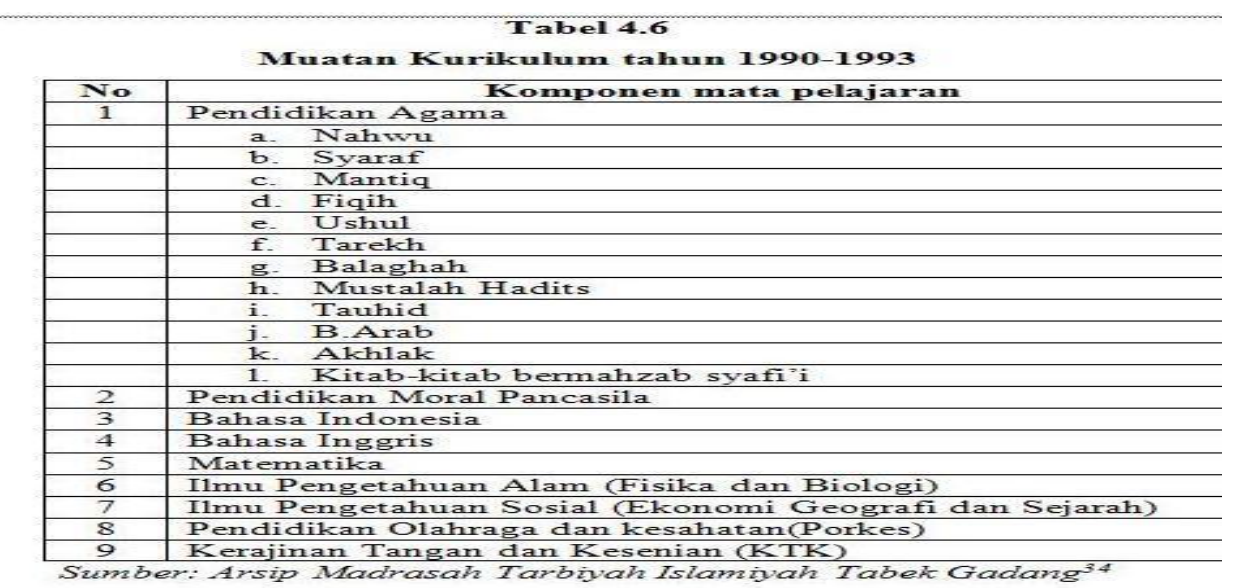

\section{Periode 1993-1998}

Pada masa periode ini Madrasah Tarbiyah Islamiyah Tabek Gadang mengalami perkembangan yang cukup baik dan mulai diminati banyak siswa.

a. Kepemimpinan

234 | Seminar Nasional Sejarah ke 4 Jurusan Pendidikan Sejarah Universitas Negeri Padang 
1) Suhaimi Abdul Wahid

Buya Suhaimi Abdul Wahid nerupakan Anak bungsu dari Syekh Abdul Wahid Ashshalihi dari istri nya di Kenagarian Simalanggang Kabipaten Lima Puluh Kota dan juga merupakan adik dari H.Syarkawi Abdul Wahid. Beliau terpanggil pulang dari perantauannya untu memberikan sumbangan tenaga dan fikirannya demi kemajuan Madrasah Tarbiyah Islamiyah Tabek Gadang yang telah dibangun ayahnya. Dimasa tuanya beliau mencoba untuk berbuat semaksimal mungkin untuk memajukan Madrasah Tarbiyah Islamiyah Tabek Gadang namun Allah berkehendak lain,belum sempat berbuat banyak, beliau mulai sakit-sakitan dan akhirnya pada awal tahun 1995 beliau dipanggil yang maha kuasa (Zil Amri, Wawancara, 06 Mei 2016). Tetapi meskipun beliau belum sempat berbuat banyak di Madrasah Tarbiyah Islamiyah Tabek Gadang ada beberapa perubahan yang terjadi pada masa kepemimpinannya.

2) Kekosongan Kepemimpinan

Setelah meninggalnya H.Suhaimi Abdul wahid maka terjadilah kekosongan kepemimpinan di Madrasah Tarbiyah Islamiyah Tabek Gadang. Tetapi untuk menggantikan peran dan tugas kepala sekolah maka ditunjuklah Buya Imam Danoer sebagai pelaksana tugas sementara (PLT). Hal ini disebabkan karena tidak adanya dari pihak keluarga yayasan atau keturunan Syekh Abdul Wahid Ashshalihi yang akan diangkat menjadi kepala sekolah dan guru-guru senior pun urung untuk mengajukan diri sebagai kepala sekolah menggantikan H. Suhaimi Abdul Wahid (Zil Amri, Wawancara, 08 Mei 2016).

b. Siswa

Pada masa kepemimpinan Buya Suhaimi Abdul Wahid Madrasah Tarbiyah Islamiyah Tabek Gadang tidak banyak berubah dari periode kepemimpinannya hanya saja jumlah siswa yang sedikit bertambah dari tahun sebelumnya.

\section{Tabel 4.8}

Jumlah Siswa Madrasah Tarbiyah Islamiyah Tabek Gadang Dari Tahun 1993-1998

\begin{tabular}{|l|l|l|}
\hline No & \multicolumn{1}{|c|}{ Tahun } & \multicolumn{1}{c|}{ Jumlah Siswa } \\
\hline 1 & 1993 & 62 Orang \\
\hline 2 & 1994 & 86 Orang \\
\hline
\end{tabular}

235 | Seminar Nasional Sejarah ke 4 Jurusan Pendidikan Sejarah Universitas Negeri Padang 


\begin{tabular}{|l|l|l|}
\hline 3 & 1995 & 105 Orang \\
\hline 4 & 1996 & 120 Orang \\
\hline 5 & 1997 & 135 Orang \\
\hline 6 & 1998 & 142 Orang \\
\hline
\end{tabular}

Sumber: Arsip Madrasah Tarbiyah Islamiyah Tabek Gadang

c. Kurikulum

Kurikulum Madrasah Tarbiyah Islamiyah Tabek Gadang Pada masa periode ini masi sama dengan kurikulum pada periode sebelumnya yaitu yaitu menggunakan kurikulum Departemen Agama yaitu memakai kurikulum Cara Belajar Siswa Aktif (CBSA).

\section{Periode1999-2005}

a. Kepemimpinan

1) Imam Danoer

Setelah dua tahun kekosongan kepemimpinan di Madrasah Tarbiyah Islamiyah Tabek Gadang yakni dari tahun 1996 sampai 1998 maka pada bulan maret tahun 1999, pihak yayasan dan didukung seluruh struktur organisasi Madrasah Tarbiyah Islamiyah Tabek Gadang memberikan kepercayaan kepada Buya Imam Danoer untuk memimpin Madrasah Tarbiyah Islamiyah Tabek Gadang. Buya Imam Danoer merupakan alumni Madrasah Tarbiyah Islamiyah Tabek Gadang pada masa kepemimpinan H. Syarkawi Abdul Wahid. Selain itu beliau juga murid yang pernah ditangani langsung oleh $\mathrm{H}$. Syarkawi Abdul Wahid (Zil Amri, Wawancara, 18 Mei 2016).

Pada masa kepemimpinan H. Imam Danoer inilah Madrasah Tarbiyah Islamiyah Tabek Gadang menunjukkan perkembangan yang cukup baik. Hal ini tidak lepas dari usaha Imam Danoer untuk menghasilkan lulusan terbaik serta mencetak para juru dakwah yang handal sehingga Madrasah Tarbiyah Islamiyah Tabek Gadang semakin dikenal Masyarakat Luas dan semakin diminati. Dalam mencapai tujuan tersebut maka H. Imam Danoer menerapkan disiplin yang tinggi serta mendatangkan guru-guru yang berkualitas ke Madrasah Tarbiyah Islamiyah Tabek Gadang (Mulyadi, Wawancara, 18 Mei 2016).

H. Imam Danoer memimpin Madrasah Tarbiyah Islamiyah Tabek Gadang cukup lama yaitu dari tahun 1999 sampai 2004. Setelah memimpin Madrasaha Tarbiyah 
Islamiyah Tabek Gadang selama lebih kurang 5 tahun beliau meninggal dunia di usia mendekati 40 tahun (Mulyadi, Wawancara, 18 Mei 2016).

2) Zil Amri Ahmad

Setelah Buya Imam Danoer meninggal, pihak yayasan menunjuk Zil Amri Ahmad sebagai salah seorang guru senior untuk menggantikan posisi H.Imam Danoer.

Zil Amri Ahmad merupakan Alumni Madrasah Tarbiyah Islamiyah Tabek Gadang sekaligus guru senior bersama Buya Fachrul Razi yang masih hidup dan masih mengabdi sampai sekarang. Beliau sekolah di Madrasah Tarbiyah Islamiyah Tabek Gadang pada masa akhir kepemimpinan H.Syarkawi Abdul Wahid dan lulus pada masa kepemimpinan H.Rusli Abdul Wahid.

Zil Amri Ahmad memimpin madrasah Tarbiyah Islamiyah Tabek Gadang hanya sekitar lebih kurang setahun yang akhirnya digantikan oleh Mulyadi S.Ag yang merupakan cucu kandung dari Syekh Abdul Wahid Ashshalihi (Zil Amri, Wawancara, 10 Mei 2016).

b. Siswa

Pada masa periode ini jumlah siswa yang datang ke Madrasah Tarbiyah Islamiyah Tabek Gadang semakin banyak (Zil Amri, Wawancara, 10 Mei 2016). Hal ini dapat dilihat pada table di bawah ini:

Tabel 4.11

\begin{tabular}{l} 
Jumlah Siswa Madrasah Tarbiyah Islamiyah Tabek Gadang Dari Tahun 1999-2005 \\
$\qquad$\begin{tabular}{|c|c|c|}
\hline No & Tahun & Jumlah Siswa \\
\hline 1 & 1999 & 153 Orang \\
\hline 2 & 2000 & 164 Orang \\
\hline 3 & 2001 & 178 Orang \\
\hline 4 & 2002 & 186 Orang \\
\hline 5 & 2003 & 193 Orang \\
\hline 6 & 2004 & 160 Orang \\
\hline 7 & 2005 & 154 Orang \\
\hline
\end{tabular} \\
\hline
\end{tabular}

c. Kurikulum 
Kurikulum yang digunakan pada masa ini masih sama dengan kurikulum pada periode sebelumnya, yaitu menggunakan kurikulum Departemen Agama yaitu memakai kurikulum Cara Belajar Siswa Aktif (CBSA). Namun Muatan kurikulumnya sedikit ditambah, yaitu pengembangan bakat siswa melaui ekstrakuriler seperti: Pramuka, Muhadarah dan lain-lain

\section{Periode 2006-sekarang}

Pada masa periode ini Madrsah Tarbiyah Islamiyah Tabek Gadang telah dipimpin oleh lulusan S1 atau sarjana. Perkembangan Madrasah Tarbiyah Islamiyah pada masa ini dapat dilihat dari :

a. Kepemimpinan

Pada masa ini Madrasah Tarbiyah Islamiyah Tabek Gadang dipimpin oleh Mulyadi S.Ag. Mulyadi merupakan cucu dari pendiri Madrasah Tarbiyah Islamiyah Tabek Gadang yaitu Syekh Abdul Wahid Ashshalihi.Beliau lahir di Ampang Gadang VII Koto Talago Kecamatan Guguak Kabupaten Lima Puluh Kota pada tanggal 28 September 1977 dan memulai jenjang pendidikannya di Sekolah Dasar No 4 Talago Ampang Gadang. Setelah tamat SD beliau melanjutkan jenjang pendidikannya ke MTsN Padang Japang karena pada saat itu Madrasah Tarbiyah Islamiyah Tabek Gadang dalam masa fakum.Setelah lulus dari MTsN Padang Japang Mulyadi melanjutkan pendidikannya ke MAN Padang Japang dengan jurusan A1 (Ilmu-Ilmu Agama). Setelah lulus dari MAN Padang Japang pada tahun 1996 Mulyadi melanjutkan pendidikan ke perguruan tinggi Institut Agama Islam Negeri (IAIN) Imam Bonjol Padang dengan jurusan Pendidikan Agama Islam Fakultas Tarbiyah dan menamatkannya pada Tahun 2001 (Mulyadi, Wawancara, 18 Mei 2016).

Setelah memperoleh gelar dari IAIN Imam Bonjol Padang pada awal tahun 2001,di penghujung tahun 2001 beliau telah mulai mengajar di Madrasah Tarbiyah Islamiyah Tabek Gadang ketika Madrasah Tarbiyah Islamiyah Tabek Gadang dipimpin oleh H.Imam Danoer. Sekitar Empat tahun mengabdi sebagai pengajar di Madrasah Tarbiyah Islamiyah Tabek Gadang maka pada tahun 2006 pimpinan Yayasan Drs.Wardi wahid, MM menunjuk beliau sebagai kepala sekolah menggantikan Zil Amri Ahmad karena tuntutan pada saat sekarang ini bahwa kepala sekolah hendaknya yang memiliki latar belakang Perguruan Tinggi atau Sarjana (Mulyadi, Wawancara, 18 Mei 2016). 
b. Siswa

Pada masa periode kepemimpinan Mulyadi, mengalami penurunan dari segi jumlah siswa. Hal ini disebabkan karena akhir-akhir ini kebanyakan dari lulusan Madrasah Tarbiyah Islamiyah Tabek Gadang akhir-akhir ini kualitasnya turun sehingga masyarakat lebih cendrung menyekolahkan anaknya ke sekolah lain namun pada tahun ini siswanya mulai banyak kembali (Vito Dasrianto, Wawancara, 20 Mei 2016).

Tabel 4.13

Jumlah Siswa Madrasah Tarbiyah Islamiyah Tabek Gadang Dari Tahun 2006-2011

\begin{tabular}{|l|l|l|}
\hline No & Tahun & Jumlah Siswa \\
\hline 1 & 2006 & 144 Orang \\
\hline 2 & 2007 & 138 Orang \\
\hline 3 & 2008 & 133 Orang \\
\hline 4 & 2009 & 127 Orang \\
\hline 5 & 2010 & 135 Orang \\
\hline 6 & 2011 & 130 Orang \\
\hline 7 & 2012 & 115 Orang \\
\hline
\end{tabular}

Sumber: Arsip Madrasah Tarbiyah Islamiyah Tabek Gadang

Tabel 4.14

Jumlah Siswa Madrasah Tarbiyah Tabek Gadang Dari Tahun 2012-2016

\begin{tabular}{|l|l|}
\hline Tahun Ajaran & Jumlah \\
\hline $2013 / 2014$ & $\mathbf{1 1 2}$ \\
\hline $2014 / 2015$ & $\mathbf{1 1 2}$ \\
\hline $2015 / 2016$ & $\mathbf{1 3 4}$ \\
\hline
\end{tabular}

Sumber: Arsip Madrasah Tarbiyah Islamiyah Tabek Gadang

c. Kurikulum

Kurikulum yang digunakan pada periode ini ada tiga macam, yaitu menggunakan kurikulum Departemen Agama yaitu memakai kurikulum Cara Belajar Siswa Aktif (CBSA). Kemudian menggunakan Kurikulum Berbasis Kompetensi (KBK) dan juga memakai Kurikulum Tingkat Satuan Pendidikan (KTSP) karena dengan berlakunya UU SISDIKNAS No. 20 tahun 2003, Madrasah-madrasah dari semua jenjang terintegrasi dalam sistem pendidikan nasional secara penuh (pasal 17 dan 18). Pada periode ini kurikulum Madrasah Tarbiyah Islamiyah Tabek 
Gadang disusun dengan mengacu pada landasan yuridis formal yang berlaku diwilayah Negara Kesatuan Republik Indonesia, yaitu: 1) Undang-undang Republik Indonesia No.20 Tahun 2003 tentang Sistem Pendidikan Nasional, 2) Peraturan pemerintah Republik Indonesia No. 19 tahun 2005 tentang Standar Nasional Pendidikan, 3) Keputusan menteri pendidikan nasional No.22 tahun 2006 tentang Standar Kompetensi dan Kompetensi Dasar jenjang pendidikan dasar dan menengah, 4) Keputusan menteri pendidikan nasional No. 23 tahun 2006 tentang Standar Kompetensi Lulusan jenjang pendidikan dasar dan menengah, 5) Keputusan menteri pendidikan nasional No. 24 tahun 2006 tentang Pengelolaan Kurikulum Tingkat Satuan Pendidikan (Mulyadi, Wawancara, 18 Mei 2016).

\section{Simpulan}

1. Madrasah Tarbiyah Islamiyah Tabek Gadang ini sebenarnya telah ada sejak tahun 1906 dalam bentuk surau yang didirikan oleh seorang Ulama, yaitu Syekh Abdul Wahid Ash-Shalihi. Pada tahun 1928 beliau mengubah bentuk majelis pendidikannya menjadi Madrasah Tarbiyah Islamiyah. Setelah Syeikh Abdul wahid Ash Shalihi meninggal pada tahun 1950 Madrasah Tarbiyah Islamiyah Tabek Gadang terus mengalami perkembangan di bawah kepemimpinan H. Syarkawi Abdul Wahid dan H. Rusli Abdul Wahid. Tetapi pada masa kepemimpinan selanjutnya yaitu H.Yusri Anwar, Madrasah Tarbiyah mengalami kemunduran bahkan sampai di tutup pada tahun 1984

2. Berkat usaha pengurus yayasan dan masyarakat Kenagarian VII Koto Talago Madrasah Tarbiyah Islamiyah Tabek Gadang dapat berdiri kembali pada tahun 1990.

3. Setelah berdiri kembali pada tahun 1990 sampai saat ini Madrasah Tarbiyah Islamiyah Tabek Gadang juga telah banyak mengalami perkembangan dari berbagai hal seperti tenaga pengajar yang dulunya rata-rata tamatan Madrasah Tarbiyah Islamiyah itu sendiri, sekarang guru-guru yang mengajar di Madrasah ini hampir semuanya telah sarjana bahkan beberapa diantaranya Pegawai Negri Sipil. Begitu juga dengan sarana pra sarana, teknnologi, jumlah siswa dan kurikulum Madrasah Tarbiyah Islamiyah ini telah banyak mengalami perkembangan, dan sudah terlihat perkembangan dari segi kepemimpinan, siswa, kurikulum, tenaga pengajar maupun sarana dan prasarana. 


\section{DAFTAR PUSTAKA}

Mustofa, Budiman. 2008. Manajemen Masjid. Solo: Ziyad Visi Media.

Nizar, Syamsul. 2005. Sejarah Dan Pergolakan Pemikiran Pendidikan Islam, Potret Timur Tengah Era Awal Dan Indonesia. Ciputat Quantum Teaching.

Ramayulis. 2002. Ilmu Pendidikan Islam. Jakarta: Kalam Mulia

- 2008. Ilmu Pendidikan Islam. Jakarta: Kalam Mulia

, 2011. Sejarah Pendidikan Islam. Jakarta: Kalam Mulia

Rada dan Soleha. 2011. Ilmu Pendidikan Islam. Bandung: Alfabeta.

Roqib, Moh. 2005. Mengunggat Fungsi Edukasi Masjid. Yogyakarta: Grafindo Litera Media.

Rukiati, Enung.K, dan Fenti Hikmawati.2006. Sejarah Pendidikan Islam di Indonesia. Bandung: Pustaka Setia.

Sastrayuda, Gumelar. "Konsep Pemberdayaan Masyarakat Berbasis Pariwisata (Hand Out Mata Kuliah Strategi Pengembangan dan Pengelolaan Resort)”, Jurnal. Diakses 20 Agustus 2016 jam 14.00

Sholeh, Chabib. 2014. Dialektika Pembangunan dengan Pemberdayaan. Bandung: Fokusmedia.

Sudarman. 2014. Arsitektur Mesjid di Minangkabau dari Masa ke Masa. Padang: IB Press.

Suharto, Edi. 2009. Membangun Masyarakat Memberdayakan Rakyat. Bandung: Refika Aditama.

Thoha, As’ad. 2011. Sejarah Pendidikan Islam. Yogyakarta: Insan Madani.

Totok Mardikanto dan Poerwoko Soebiato. 2015. Pemberdayaan Masyarakat: Dalam Pespektif Kebijakan Publik. Bandung: Alfabeta.

Uhbiyati, Nur. 1997. Ilmu Pendidikan Islam. Bandung: Pustaka Setia.

Usman, Hasan. 1986. Metode Penelitian Sejarah. Jakarta: Pembinaan Prasarana dan Sarana Perguruan Tinggi Agama/IAIN.

Yani, Ahmad. 2009. Panduan Memakmurkan Masjid. Depok: Al-Qalam.

W.J.S Poerwadarminta, 1995. Kamus Besar Bahasa Indonesia. Jakarta: Balai Pustaka. 